\title{
$\lambda$-cyhalothrin induced genotoxicity in freshwater fish Labeo rohita
}

\author{
P. D. Gadhave ${ }^{1}$, R. S. Brar ${ }^{1}$, H. S. Banga ${ }^{1}$ and A. Dhawan ${ }^{2}$ \\ 1. Department of Veterinary Pathology, College of Veterinary Science, Guru Angad Dev Veterinary and Animal \\ Sciences University (GADVASU), Ludhiana-141004, India; 2. Department of Aquaculture, College of Fisheries \\ Science, GADVASU, Ludhiana - 141004, India \\ Corresponding author: P. D. Gadhave, email: pdgadhave@gmail.com \\ RSB: rsbrar@email.com, HSB: bangahs3@yahoo.com, AD: dhawanasha@gmail.com \\ Received: 20-03-2014, Revised: 17-05-2014, Accepted: 21-05-2014, Published online: 20-06-2014
}

doi: $10.14202 /$ vetworld.2014.412-415

How to cite this article: Gadhave PD, Brar RS, Banga HS and Dhawan A (2014) $\lambda$-cyhalothrin induced genotoxicity in freshwater fish Labeo rohita, Veterinary World 7(6): 412-415.

\begin{abstract}
Aim: To study the genotoxicity of $\lambda$-cyhalothrin in Labeo rohita by determining the induction of micronuclei (MN) in erythrocytes.

Materials and Methods: The genotoxicity of to $\lambda$-cyhalothrin was studied using 300 Labeo rohita fingerlings with reference the guidelines of Organization for Economic Co-operation and Development (OECD) 204 except the loading density which was higher than the recommended density $1.0 \mathrm{~g} / \mathrm{l}$ to reduce the chemical loss. The disinfection and acclimation for 14 days were done at the site of experiment. Fish were divided into five groups of 20 fish each. Group I exposed to $0.27 \mu \mathrm{g} / 1 \mathrm{while}$ Group II exposed to $0.054 \mu \mathrm{g} / 1$ of $\lambda$-cyhalothrin. There were three control groups, Group III contain only water, Group IV vehicle control with $0.27 \mu \mathrm{g} / \mathrm{l}$ acetone and Group V positive control with $5 \mathrm{mg} / \mathrm{l}$ cyclophosphamide. The experiment was conducted in triplicate. Water quality parameters like temperature, $\mathrm{pH}$, total hardness and total alkalinity were measured on every 15 days. Twenty litres of water from each aquaria was exchanged daily with water containing respective concentration of chemical to maintain water quality and chemical concentration. On $15^{\text {th }}, 30^{\text {th }}$ and $45^{\text {th }}$ day blood was collected from four fish per aquaria and pooled to get two blood samples. Three blood smears were prepared from each blood sample and stained with Giemsa-Wright. For every blood smear MN frequency per 1000 erythrocytes was counted. Finally the MN assay was given as average frequency per group.
\end{abstract}

Results: The highest frequency of MN was observed on $15^{\text {th }}$ day in dose dependent manner. However there was time dependent decrease in frequency of $\mathrm{MN}$ on $30^{\text {th }}$ and $45^{\text {th }}$ day.

Conclusions: $\lambda$-cyhalothrin was genotoxic to Labeo rohita and micronuclei assay is suitable for detecting genotoxicity of $\lambda$ cyhalothrin in Labeo rohita due to acute exposures.

Keywords: $\lambda$-cyhalothrin, genotoxicity, Labeo rohita, micronuclei

\section{Introduction}

The industrial development and rapid urbanization has led to development of polluted zones discharging potentially toxic compounds in the environment. Especially, indiscriminate use of pesticides resulted in contamination of aquatic system has now become a global problem and is being extensively researched worldwide [1]. Most of the pesticides are genotoxic [2]. Means these chemicals have the potential of causing DNA damage, increased incidences of neoplasia and adverse effect on vitality and progeny of aquatic animals, which may reduce the productivity of aquaculture. Among different groups of pesticides newly introduced synthetic pyrethroids were once considered as relatively safe [2], but researches had reported the genotoxicity of this group of pesticides [3,4]. Micronucleus (MN) test which is one of the useful methods to detect genotoxicity in aquatic animals [5].

India is one of the leading carp producers in the world. The most important species being Labeo rohita

Copyright: The authors. This article is an open access article licensed under the terms of the Creative Commons Attribution License (http://creativecommons.org/licenses/by/2.0) which permits unrestricted use, distribution and reproduction in any medium, provided the work is properly cited. (rohu), Catla catla and Cirrhinus mrigala. Among all rohu is the most preferred species and in last decade contribute about $35 \%$ of the total carp production in India [6]. However, there were no genotoxicity studies of $\lambda$-cyhalothrin on one of the most important fish species of India i.e. Labeo rohita.

Therefore the present investigation aimed at finding the genotoxicity of $\lambda$ - cyhalothrin in rohu using micronuclei assay.

\section{Materials and Methods}

Ethical approval: The experimental protocol was approved by the Institutional Animal Ethics Committee.

Organization for Economic Co-operation and Development (OECD) guidelines: To study the genotoxicity of $\lambda$-cyhalothrin in Labeo rohita, the prolonged toxicity experiment was conducted with reference to the guidelines of OECD 204 except the loading density which was higher than the recommended density $1.0 \mathrm{~g} / 1$ to reduce the chemical loss.

Chemicals: Analytical grade $\lambda$-cyhalothrin, ethyl 3aminobenzoate methanesulfonate, Sigma-Aldrich, USA and cyclophosphamide obtained from Sigma-Aldrich, 


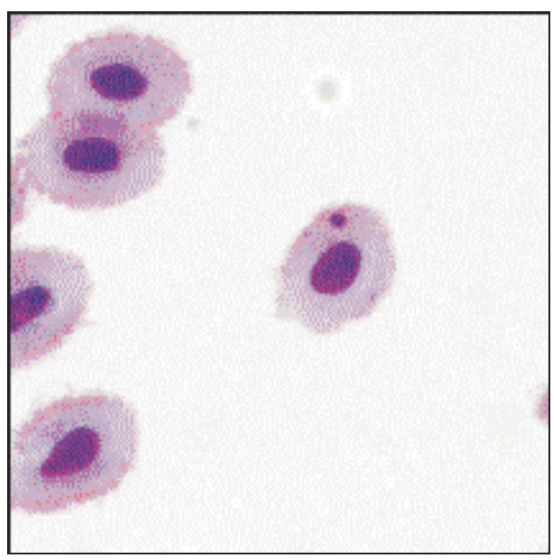

Table-1: Micronuclei frequency in fish exposed to $\lambda$-cyhalothrin

\begin{tabular}{lccc}
\hline MN assay $(\%)$ & Day 15 & Day 30 & Day 45 \\
\hline Group I $(0.27 \mu \mathrm{g} / \mathrm{l})$ & $1.94^{\mathrm{p}} \pm 0.22$ & $0.83^{\mathrm{pst}} \pm 0.19$ & $0.56^{\mathrm{p}} \pm 0.12$ \\
Group II $(0.054 \mu \mathrm{g} / \mathrm{l})$ & $1.11^{\mathrm{q}} \pm 0.20$ & $0.50^{\mathrm{pt}} \pm 0.12$ & $0.39^{\mathrm{p}} \pm 0.12$ \\
Group III $(5 \mathrm{mg} / \mathrm{l}$ cyclophosphamide $)$ & $3.22^{\mathrm{r}} \pm 0.32$ & $1.39^{\mathrm{ps}} \pm 0.16$ & $0.67^{\mathrm{p}} \pm 0.20$ \\
Group IV $(0.27 \mu \mathrm{g} / \mathrm{l}$ of acetone) & $0.30^{\mathrm{s}} \pm 0.12$ & $0.28^{\mathrm{r}} \pm 0.10$ & $0.22^{\mathrm{p}} \pm 0.10$ \\
Group V (Only Water) & $0.33^{\mathrm{s}} \pm 0.14$ & $0.30^{\mathrm{r}} \pm 0.11$ & $0.24^{\mathrm{p}} \pm 0.09$ \\
\hline
\end{tabular}

Values indicate mean \pm S.E. Values lacking common superscripts significantly different at $P<0.05$ column wise.

Figure-1: Single round micronucleus in erythrocyte of Labeo rohita. (Giemsa-Wright X 100).

USA. Analytical grade acetone and potassium permanganate obtained from SD Fine-Chem, Mumbai, India.

Fish: The fingerlings of Labeo rohita used for this experiment were $8.28 \pm 1.42 \mathrm{~cm}$ in length and $10.13 \pm$ $1.84 \mathrm{~g}$ in weight brought from Nanokey fish seed hatchery, Nanokey, district Patiala, Punjab.

Pre-treatment and acclimatization: To reduce the chances of infection and microbial load, on arrival of fish to laboratory, one minute dip of $500 \mathrm{mg} / \mathrm{l}$ potassium permanganate was given. Feeding was done twice a day@2\% of initial biomass with commercially available feed. Compressors were used to maintain the continuous supply of air to aquaria. The light and dark cycles of $12 \mathrm{~h}$ was maintained throughout the experiment.

Experimental procedure: There were five groups each containing twenty fish of approximate same size placed in plastic aquaria of 35 litres capacity containing 30 litres dechlorinated water. Group I exposed to $0.27 \mu \mathrm{g} / 1$ while Group II exposed to $0.054 \mu \mathrm{g} / 1$ of $\lambda$-cyhalothrin. There were three control groups, Group III contain only water, Group IV vehicle control with $0.27 \mu \mathrm{g} / 1$ acetone and Group $\mathrm{V}$ positive control with $5 \mathrm{mg} / \mathrm{l}$ cyclophosphamide. The experiment was conducted in triplicate. 20 litres of water was exchanged daily with reducing to maintain the water quality and constant chemical concentrations. On $15^{\text {th }}, 30^{\text {th }}$ and $45^{\text {th }}$ day blood was drawn using tuberculin syringes rinsed with $1 \%$ heparin solution from caudal vein of fish anesthetized in ethyl 3-aminobenzoate methanesulfonate, Sigma-Aldrich, USA, $100 \mathrm{mg} / \mathrm{l}$ which were later sacrificed and feeding was adjusted after every sampling. The blood samples from two fish were pooled to form one sample. Two samples per aquaria were analysed for MN assay. Three blood smears were prepared from each blood sample on clean glass slide and air dried for one day. The blood smears were stained with Giemsa-Wright stain for two minutes followed by dilution with phosphate buffer ( $\mathrm{pH}$ 6.8) for twenty minutes. Stained slides then thoroughly washed with distilled water and air dried. Before observing slides were differentiated with methanol followed by xylene for clearance. For every slide thousand well separated erythrocytes were counted. Round or ovoid bodies smaller than the one-third of the main nucleus with same staining as of nucleus, were scored as micronuclei.

Statistical analysis: The result was expressed as mean \pm standard error (SE). To assess the significance of the differences at each sampling time, statistical analysis was performed using one way analysis of variance (ANOVA) with significance assessed at $95 \%$ confidence level followed by Tukey's test was applied using computerized program SPSS 16.0 Inc. USA.

\section{Results}

The water quality parameters during the experiment were as follows: $\mathrm{pH}(7.49 \pm 0.79)$, temperature $(28.12 \pm$ $\left.0.85^{\circ} \mathrm{C}\right)$, total hardness $(283.12 \pm 4.45 \mathrm{mg} / \mathrm{l})$ and total alkalinity $(280 \pm 3.89 \mathrm{mg} / \mathrm{l})$ and dissolved oxygen $(8.3$ $\pm 0.74 \mathrm{mg} / \mathrm{l})$, during the experiment.

The micronuclei were also found in fish of group $\mathrm{V}$, i.e. water control (Figure-1) on every sampling time. The frequencies of $\mathrm{MN}$ were highest on $15^{\text {th }}$ day for group I (1.94 \pm 0.22$)$ II $(1.11 \pm 0.20)$ and III (3.22 \pm $0.32)$ i.e. for both the $\lambda$-cyhalothrin concentrations and for cyclophosphamide. Also the frequencies of $\mathrm{MN}$ on $15^{\text {th }}$ day for group I, II and III were statistically different from each other as well as from both the controls i.e. group IV $(0.30 \pm 0.12)$ and group $\mathrm{V}(0.33 \pm 0.14)$. On $30^{\text {th }}$ day $\mathrm{MN}$ frequencies of Group I, II and III were statistically non-significant from each other, however all these groups (I, II and III) differ statistically from both controls. On $45^{\text {th }}$ day no statistical difference was observed in $\mathrm{MN}$ frequencies of any experimental group (Table-1). The frequency of MN always remained high in positive control while no significant difference was observed in $\mathrm{MN}$ frequencies of water and vehicle control.

\section{Discussion}

In present study frequency of micronuclei increased with concentration and decreased with time. These findings were congruent with the report of Ali et al [7], who observed the similar effect on micronuclei frequency 
due to chlorpyrifos exposure to Channa stratus. However Bahari et al [8] reported the both concentration and time-dependent increases in $\mathrm{MN}$ frequency in fish due to chemical exposure. The difference in MN frequency may be due to the fact that $\mathrm{MN}$ frequency probably varies depending upon genotoxic compound, test organism, and the life cycle of the cells [9]. In this study an alkylating agent cyclophosphamide a known genotoxic compound was used as positive control. The test group treated with cyclophosphamide showed a significant increase in $\mathrm{MN}$ frequency when compared with the results from the negative control group as observed by Ozkan et al [10] in peripheral erythrocytes of Nile tilapia, Oreochromis niloticus. There was no significant alteration in $\mathrm{MN}$ frequency of vehicle control and negative control group indicating that vehicle (acetone) did not influence the $\mathrm{MN}$ frequencies in treatment.

Fish can be considered as useful genetic models for studying genotoxic potential of different pollutants [11]. The MN assay is found to be a sensitive for evaluating genotoxicity of compounds in fish under controlled conditions [12]. The findings of the present study of genotoxic potential of $\lambda$-cyhalothrin were congruent with findings of [13] in fish.

Synthetic pyrethroids is an important pesticide group used in agriculture as well as aquaculture for control of harmful insects. Fish farmers are still using such pesticides for control of ectoparasites in aquaculture [14]. Lambda cyhalothrin one of the synthetic pyrethroid is utilized as pesticide for agricultural purpose which may produce fish kill phenomenon in different parts of the world. It is extremely toxic to aquatic invertebrates [15]. Synthetic pyrethroids are known to produce chromosomal changes and reproductive problems in fishes [16]. Pesticides also affects the energy metabolism in fish [17] and especially results in reduced growth rate, delayed or reduced hatching and high mortality after hatching in early life stages [18].

Present report on the genotoxic potential of $\lambda$ cyhalothrin in Labeo rohita suggested about its potential danger to aquatic organisms, especially to fish. This study also revealed that micronuclei assay was more suitable to study the acute toxicity of $\lambda$-cyhalothrin in Labeo rohita as no significant differences were observed in any group on prolonged expo-sures. However MN frequency depends on number of factors as discussed above hence more investigations were needed to standardise the MN assay and genotoxic potential of this pesticide under field conditions.

\section{Conclusions}

Present study revealed that $\lambda$-cyhalothrin is genotoxic to Labeo rohita and utility of micronuclei assay to detect the genotoxicity due to acute exposure of pesticide in fish under experimental conditions.

\section{Authors' contributions}

The present study is a part of PDG's Ph.D. dissertation. RSB and HSB designed the experiments.
AD approved the experimental protocol. PDG did the experiment. PDG and RSB drafted the manuscript and HSB critically reviewed the manuscript. AD provided critical suggestions in conducting the experiment. All authors read and approved the final manuscript.

\section{Acknowledgements}

The authors are thankful to Director of research, Guru Angad Dev Veterinary and Animal Sciences University (GADVASU) and Dean, College of Veterinary Science, GADVASU for providing facilities and funds for the research. The first author is thankful to GADVASU for providing merit scholarship during the research.

\section{Competing interests}

The authors declare that they have no competing interests.

\section{References}

1. Dutta, H. M. and Dalal, R. (2008) The effect of endosulfan on the ovary of Bluegill Sunfish: A histopathological study (Lepomis macrochirus sp). Int. J. Environ. Res. Publ. Health, 2(3):215-224.

2. Kaushik, P. and Kaushik, G. (2007). An assessment of structure and toxicity correlation in organochlorine pesticides. J. Hazard. Materials, 143:102-111.

3. Ansari, R.A., Rahman, S., Kaur, M., Anjum, S. and Raisuddin, S. (2011) In vivo cytogenetic and oxidative stress-inducing effects of cypermethrin in freshwater fish, Channa punctata Bloch. Ecotoxicol Environ Saf.,74(1):150-156.

4. Fetoui, H., Feki, A., Ben Salah, G., Kamoun, H., Fakhfakh, F. and Gdoura, R. (2013) Exposure to lambda-cyhalothrin, a synthetic pyrethroid, increases reactive oxygen species production and induces genotoxicity in rat peripheral blood. Toxicol Ind Healh. doi: 10.1177/0748233713475516.

5. Ergene, S., Cavas, T., Celik, A., Koleli, N., Kaya, F., and Karahan, A. (2007) Monitoring of nuclear abnormalities in peripheral erythrocytes of three fish species from the Goksu Delta (Turkey): genotoxic damage in relation to water pollution. Ecotoxicology, 16:385-391.

6. Food and Agriculture Organization of the United Nations (FAO) (2012) The State of World Fisheries and Aquaculture. Rome, 2012: 230.

7. Ali, D., Nagpure, N. S., Kumar, S., Kumar, R. and Kushwaha, B. (2008) Genotoxicity assessment of acute exposure of chlorpyrifos to freshwater fish Channa punctatus (Bloch) using micronucleus assay and alkaline single-cell gel electrophoresis. Chemosphere, 71:1823-1831.

8. Bahari, I. B., Noor, F. M. and Daud, N. M. (1994) Micronucleated erythrocytes as an assay to assess actions by physical and chemical genotoxic agents in Clarias gariepinus. Mutat Res., 313:1-5.

9. Grisolia, C. K. and Cordeiro, C. M. T. (2000) Variability in micronucleus induction with different mutagens applied to several species of fish. Genet Mol Biol., 23: 235-239.

10. Ozkan, F., Gunduz, S. G., Berkoz, M. and Hunt, A. O. (2011) Induction of micronuclei and other nuclear abnormalities in peripheral erythrocytes of Nile tilapia, Oreochromis niloticus, following exposure to sublethal cadmium doses. TurkJZool., 35(4): 585-592.

11. Braunbeck, T., Boettcher, M., Hollert, H., Kosmehl, T., Lammer, E., Leist, E., Rudolf, M. and Seitz, N. (2005) Towards an alternative for the acute fish LC (50) test in chemical assessment: the fish embryo toxicity test goes multi-species- an update. Altex., 22(2):87-102.

12. Bolognesi, C., Perrone, E., Roggieri, P., Pampanin, D. M. and Sciutto, A. (2006) Assessment of micronuclei induction in peripheral erythrocytes of fish exposed to xenobiotics under controlled conditions. Aquat. Toxicol., 78(Suppl 1): 93-98. 
13. Gokalp, M. F. D. and Guner, U. (2011) Induction of micronuclei and nuclear abnormalities in erythrocytes of mosquito fish (Gambusia affinis) following exposure to the pyrethroid insecticide $\lambda$-cyhalothrin. Mutat Res., 726(2): 104-108.

14. Kumar, A., Sharma, B., Pandey, R. S. (2010) Toxicological assessment of pyrethroid insecticides with special reference to cypermethrin and $\lambda$-cyhalothrin in freshwater fishes. Int. J. Biol.Med. Res., 1:315-325.

15. Haya, K., Burridge, L. E., Davies, I. M. and Ervik, A. (2005) A review and assessment of environmental risk of chemicals used for the treatment of sea lice infestations of cultured salmon. In: B. Hargrave (Ed.), Handbook of Environmental
Chemistry, Water Pollution, Part M, Vol. 5, p305-341.

16. Moore, A. and Waring, C. P. (2001) The effects of synthetic pyrethroid pesticide on some aspects of reproduction in Atlantic salmon (Salmo salar L.) Aquat. Toxicol., 52: 1-12.

17. El-Sherif, M. S., Ahmed, M. T., El-Damasoury, M. A. and E Nwishy, N. H. K. (2009) Evaluation of diazinon toxicity on Nile tilapia (Oreochronus niloticus) J. Fish. Aquat Sci., 4: 169-177.

18. Richterova, Z., Machova, J., Stara, A., Tumova, J., Velisek, J., Sevcikova, M. and Svobodova, Z.(2014) Effects of cyhalothrin-based pesticide on early life stages of common carp (Cyprinus carpio L.) Biomed. Res. Int. 2014: Article ID 107373.

$* * * * * * * *$ 